\title{
High precision vertical gravity gradient determination in Croatia
}

\author{
M. Repanić • M. Kuhar • I. Malović
}

Received: 29 January 2014/ Accepted: 14 February 2015/Published online: 4 March 2015

(C) Akadémiai Kiadó 2015

\begin{abstract}
The paper depicts high precision vertical gravity gradient determination for the purpose of height reduction in order to connect absolute gravity determinations and high precision relative gravity measurements. Measurements were performed with two Scintrex Autograv CG-3M gravity meters at two absolute gravity stations. Measurement procedure was chosen to reduce influence of hysteresis effect and instrumental noise. Investigation on adjustment model best describing the measurements and their stochastic properties has been carried out, as well as investigations on number of measurements and number of readings influence on estimated vertical gravity gradient precision. On the basis of experimental measurements, it was found expedient to incorporate quadratic daily drift into a functional model. Mathematical correlation of subsequent measurements can then be taken into account by stochastic model. However, if daily drift is modelled as a linear function, better results are accomplished if no correlation is taken into account. Furthermore, measurement of the gravity difference between two levels in 7 iterations ( 4 observations at each level) by two gravity meters was found sufficient for high precision vertical gravity gradient determination. Moreover, measurement in 6 iterations or conducting more than 10 readings in each observation series does not provide significantly different results. Vertical gradients were determined with standard deviations from 3 to $6 \mathrm{nms}^{-2} / \mathrm{m}$, which allow conversion between reference heights of absolute and relative gravity measurements with precision better than $0.01 \mu^{\mathrm{ms}}{ }^{-2}$.
\end{abstract}

Keywords Vertical gravity gradient $\cdot$ High precision gravimetry $\cdot$ Scintrex CG-3M

\section{Introduction}

Vertical gravity gradient represents a change of gravity with height (Torge 1989):

M. Repanić $(\bowtie) \cdot$ I. Malović

State Geodetic Administration, Zagreb, Croatia

e-mail: marijarepanic@yahoo.com

M. Kuhar

University of Ljubljana Faculty of Civil and Geodetic Engineering, Ljubljana, Slovenia 


$$
W_{z z}=\frac{\partial^{2} W}{\partial z^{2}}=\frac{\partial g}{\partial z}
$$

where $W$ is the gravity potential, $g$ is the gravity and $z$ is the vertical coordinate in the local gravity field system. From (1) follows the reduction of measured gravity from the reference height of an instrument to the bench mark:

$$
\partial g_{i}=W_{z z} i
$$

where $i$ represents the reference height of the instrument sensor. Because of the influence of regional and local topography and density anomalies in subsurface layers of the Earth crust, the real value of vertical gradient can significantly differ from normal value. Hence, the precise true value is of particular importance in connection with absolute and high precision relative gravity measurements (Csapó and Völgyesi 2002, 2004; Dykowski 2012).

The change of vertical gravity gradient with height (influenced by local topography) is largest within a few tens of centimetres above the ground and it can be taken in consideration as a second order function, while about $40 \mathrm{~m}$ above the ground the nonlinearity of the vertical gradient disappears (Torge 1989; Dykowski 2012). Thus, measurements only at two heights along the perpendicular line in order to determine vertical gravity gradient for the purpose of height reduction does not provide sufficient accuracy (Csapó and Völgyesi 2002, 2004).

Csapó and Völgyesi (2004) state two methods for conversion between reference heights of absolute and relative gravity measurements. First involves determination of vertical gravity gradient with specified procedure (linear or quadratic approximation method, same specific instrument heights, etc.) uniformly applied for all gravity points. Second involves measurement of actual gravity difference at specific point between average reference height of absolute instrument and reference height of relative instrument. The residual height reductions (from average to actual reference height of the absolute instrument and from reference height of relative instrument to the bench mark) are insensitive of approximation method (linear or quadratic) because of the small differences in height (10-20 and $5-15 \mathrm{~cm}$, respectively).

Thus, if the measurements are performed at heights near reference heights of absolute and relative instrument, measurements at two heights can provide sufficient accuracy for conversion between reference heights of absolute and relative gravity measurements.

Motivation of this work was to determine how precise the vertical gravity gradient can be determined from experimental measurements preformed with two Scintrex Autograv CG-3M gravity meters, taking into account their known instrumental properties and, on the other hand, given the limitations of the available equipment. Also, investigation on adjustment model best describing the measurements and their stochastic properties has been carried out, as well as investigation on number of measurements and number of readings influence on estimated vertical gravity gradient precision.

\section{Measurements}

Measurements for the purpose of vertical gravity gradient determination were performed in April 2013 at two absolute gravity stations: AGT02 Zagreb Maksimir (on April 9th) and AGT03 Zagreb Puntijarka (on April 30th). In addition, at station AGT03 measurements have been repeated twice (on October 1st and October 15th 2014). Absolute measurements 
at both stations have been performed in June 1996 by experts from former German Institut für Angewändte Geodäsie (IfAG), today the Bundesamt für Kartographie und Geodäsie $(B K G)$, with the absolute gravity meter FG5-101. According to Richter et al. (1999) and Report on absolute gravity network of Republic of Croatia data of Croatian Geodetic Institute (CGI) from 2004, on that occasion vertical gravity gradient was determined with LaCoste \& Romberg (LCR) meter model D-21F of BKG equipped with an electronic feedback system from 10 readings at each of reference levels 0.06 and $1.31 \mathrm{~m}$ (Table 1). According to first Report on Project of connection of Republic of Croatia to International Gravity Standardization Network of Faculty of Geodesy University of Zagreb from 1997, station AGT03 was selected as alternative station in Zagreb because absolute measurements at station AGT02 could not be preformed with sufficient accuracy. In particular, because of sliding roof, temperature requirements were not satisfied. However, both stations are later included in Zero order gravity network of Republic of Croatia (Bašić et al. 2006). Moreover, the stations serve as provisory gravity calibration line. Since absolute measurements in Croatia were preformed only in 1996 at four stations (including AGT02 and AGT03) and twice during years 1999 and 2000 at two other stations, new absolute gravity measurements are planned in Croatia (Repanić et al. 2014).

New vertical gravity gradient measurements were performed with two Scintrex Autograv CG-3M gravity meters (serial no. 4372 and 4373) of Croatian State Geodetic Authority (SGA), before in possession of CGI, by experts from SGA, and at station AGT02 together with students from Faculty of Geodesy, University of Zagreb.

The meters were involved in several campaigns on the territory of Republic of Croatia (measurements of Fundamental Gravity Network), while the 4373 meter was also involved in measurements of Slovenian Fundamental Gravity Network. During test measurement for the purpose of calibration of relative gravity meters preformed by the experts from CGI, and latter SGA, significant hysteresis effect has been noticed especially for the 4372 meter. In addition, same meter exhibits quadratic daily drift.

Because of the noticed hysteresis effect, which is particularly emphasized for 4372 meter, the meters where left to stabilize for about an hour after arrival at the station. During that period the readings were recorded (Fig. 1).

Since these were only the experimental measurements and no better stand was available, massive wooden stand with fixed legs of the Wild T4 universal instrument was used for that purpose (Fig. 2). As stated above, in order to provide sufficient accuracy for conversion between reference heights of absolute and relative gravity measurements, measurements should be preformed close to reference heights of relative and absolute instruments. In Croatia all absolute measurements are preformed with FG5 instrument, and new measurements are also planed to be performed with FG5 instrument, while for relative measurements in national gravity networks only Scintrex CG-3M and CG-5 are used. However, because of the properties of the stand and dimensions of the concrete pillars it was possible to perform the measurements only at two levels: 0.26 and $1.47 \mathrm{~m}$, although

Table 1 Measurements at absolute stations in 1996

\begin{tabular}{lllll}
\hline Station & $H(\mathrm{~m})$ & $g\left(\mu \mathrm{ms}^{-2}\right)$ & $W_{z z}\left(\mu \mathrm{ms}^{-2} / \mathrm{m}\right)$ & $\sigma_{W z z}\left(\mu \mathrm{ms}^{-2} / \mathrm{m}^{2}\right)$ \\
\hline AGT02 & 144.767 & $9806,622.590$ & -3.24 & 0.012 \\
AGT03 & 987.689 & $9805,104.397$ & -4.09 & 0.012 \\
\hline
\end{tabular}


(a)

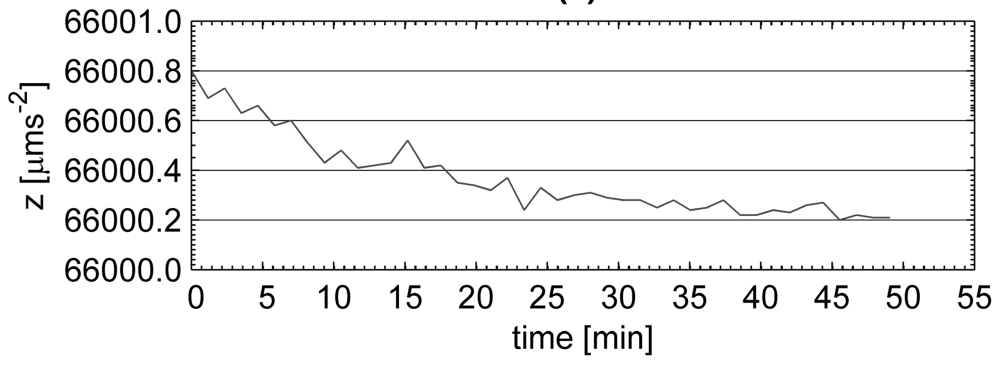

(b)

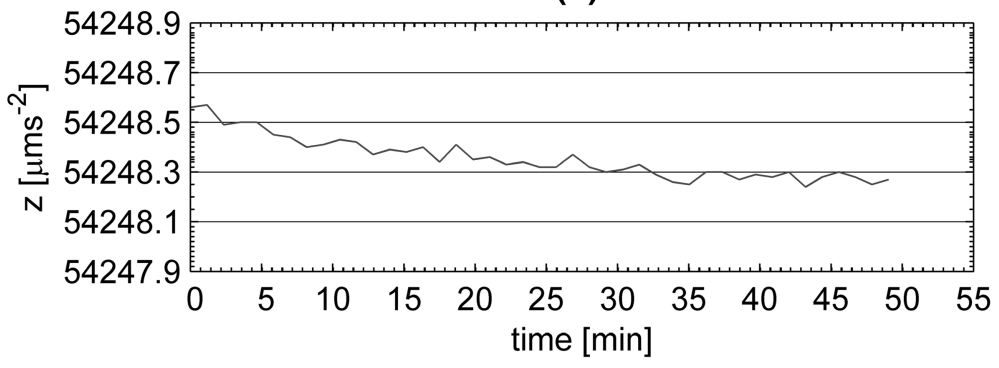

(c)

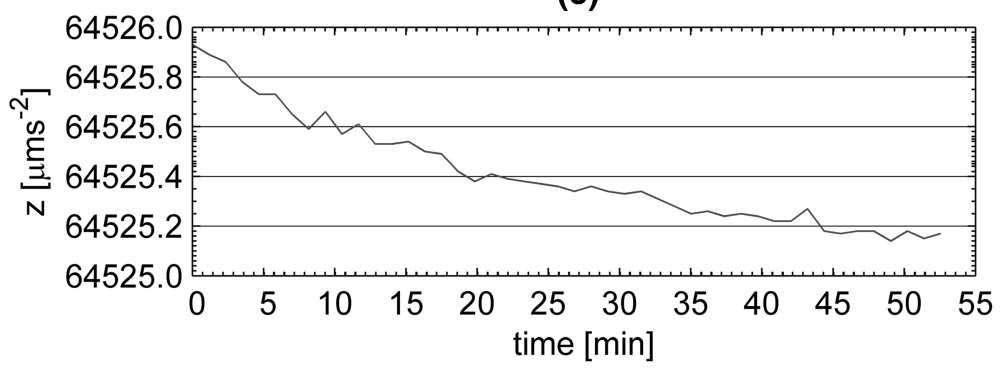

(d)

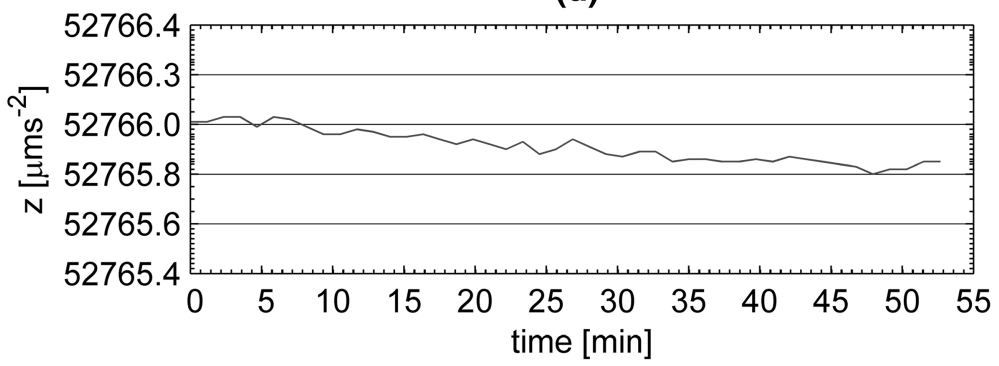

Fig. 1 Gravity readings during stabilization period: a meter 4372 and b meter 4373 at station AGT02 on April 9th 2013, c meter 4372 and d meter 4373 at station AGT03 on April 30th 2013

the reference height of the FG5 instrument $(1.30 \mathrm{~m})$ was tried to be reached. Heights were measured with $\mathrm{mm}$ precision upon each level change. The measurements were preformed simultaneously with two meter. The gravity difference between two levels was measured 7 
Fig. 2 Measurements at station AGT02

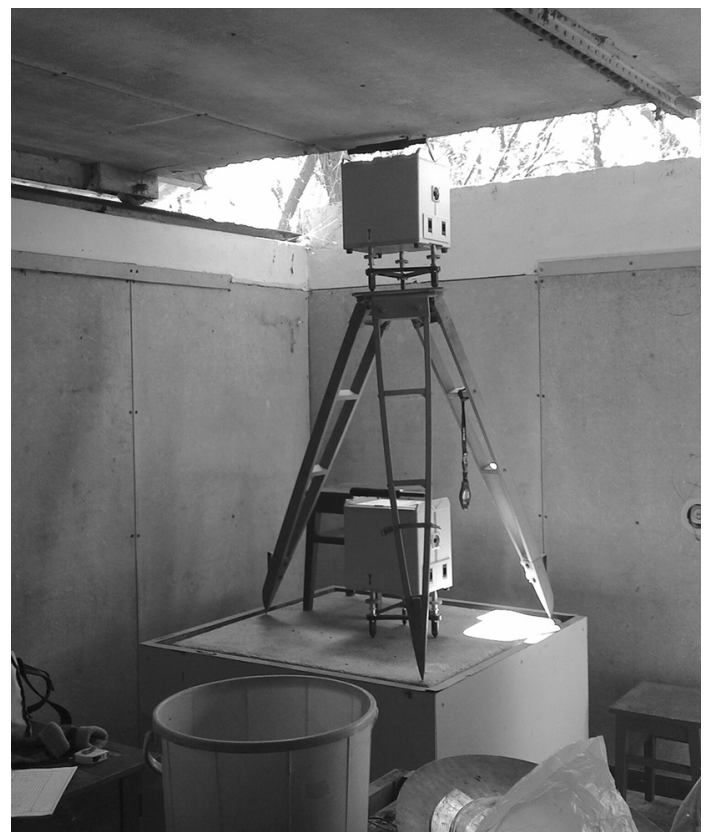

times with each meter. Hence, 8 independent observation series were preformed with each meter, four at each level. Instruments were left to stabilize for $10 \mathrm{~min}$ after each level change. To filter out instrumental noise (noticeable in Fig. 1), each observation series involved 15 independent $60 \mathrm{~s}$ readings (except on October 1st 2014, when each observation series involved 14 readings). Figure 3 depicts typical variation of readings from one

(a)

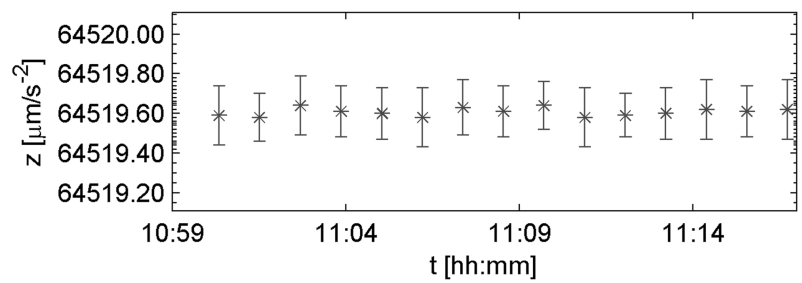

(b)

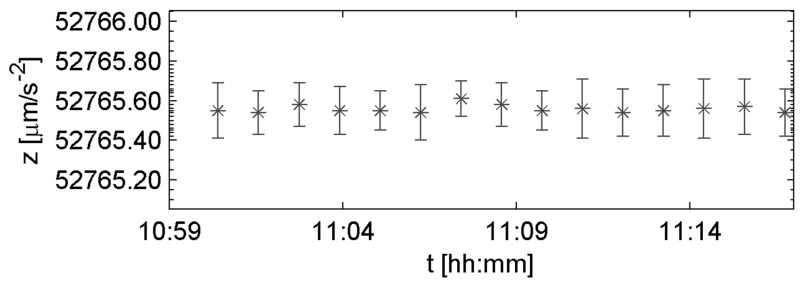

Fig. 3 Gravity readings and their standard deviations of the 5th observation series at station AGT03 on April 30th 2013 for a meter 4372 and b meter 4373 
(a)

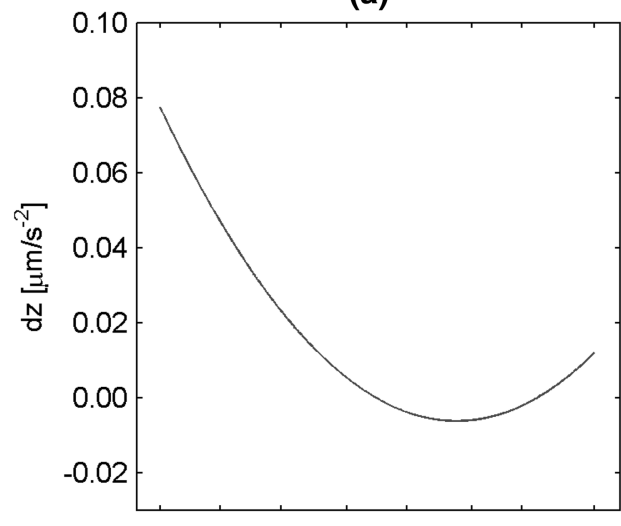

(c)

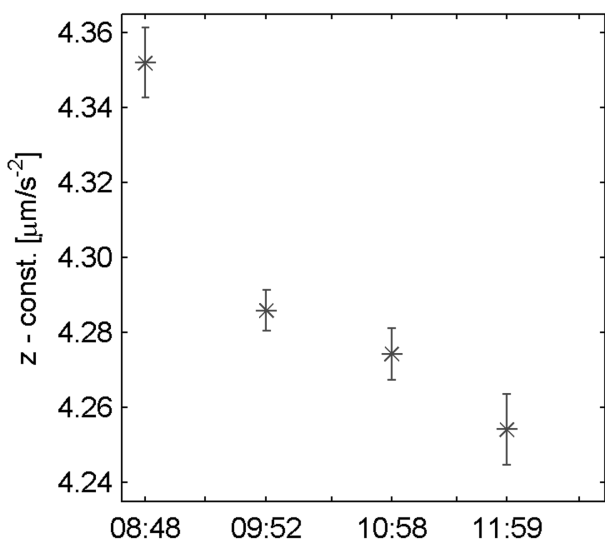

(e)

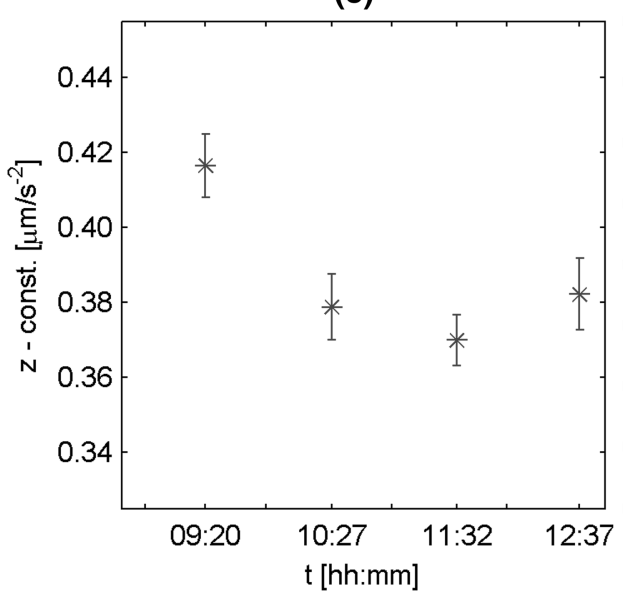

(b)

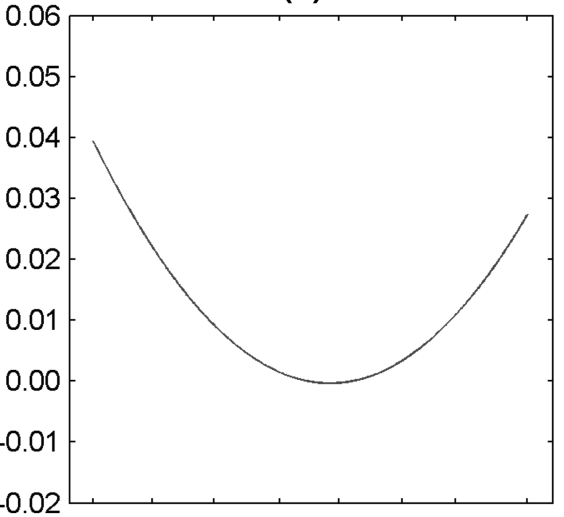

(d)

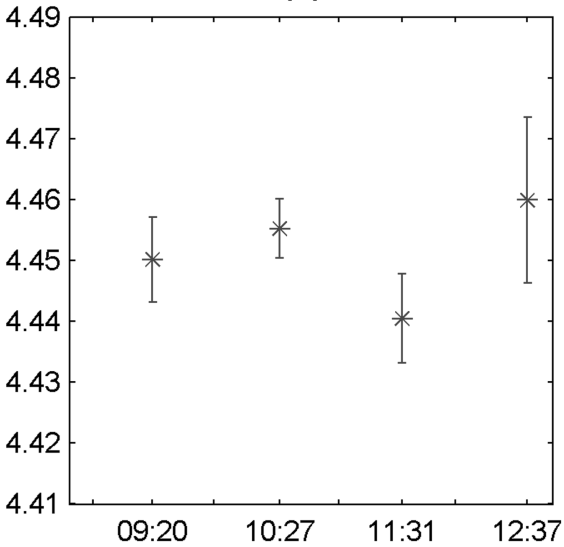

(f)

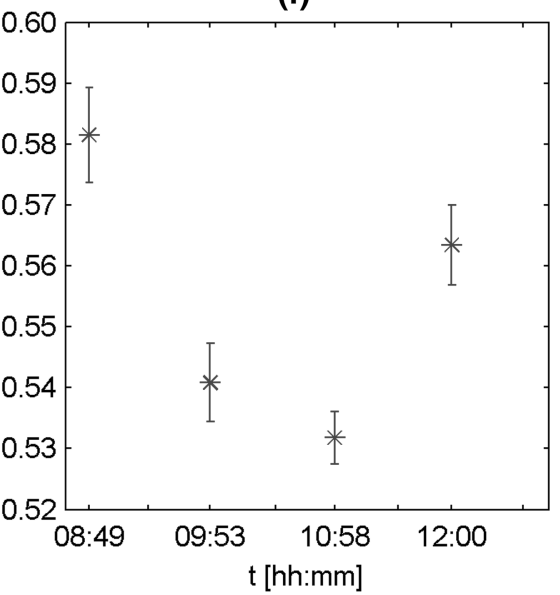

Fig. 4 Drift estimated by F2 S1 model for: a meter 4372, b meter 4373; observations with its standard deviations at lower level for: c meter 4372, d meter 4373 and at higher level for: e meter 4372, f meter 4373 at station AGT02 on April 9th 2013 
(a)

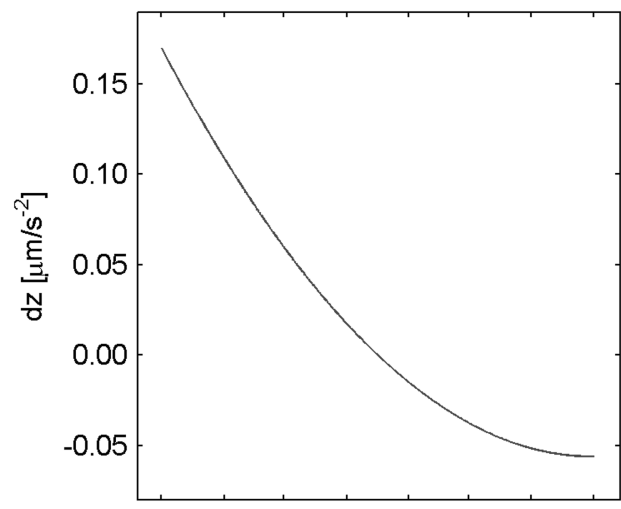

(c)

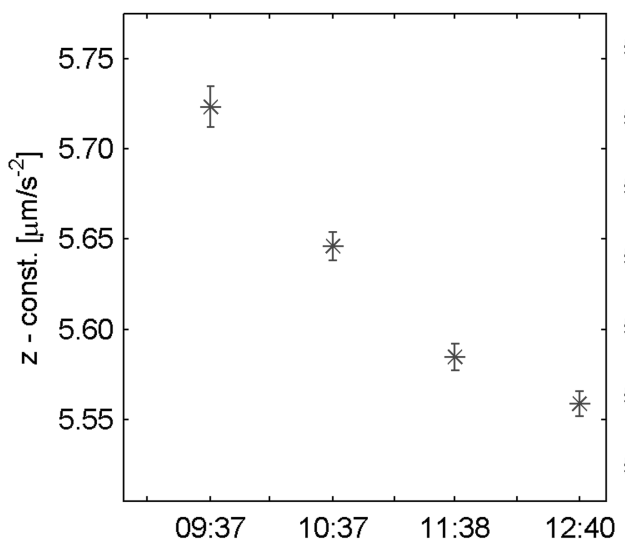

(e)

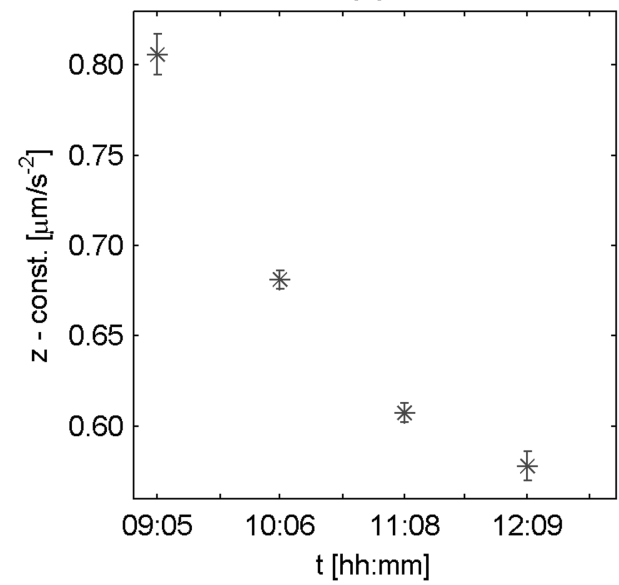

(b)

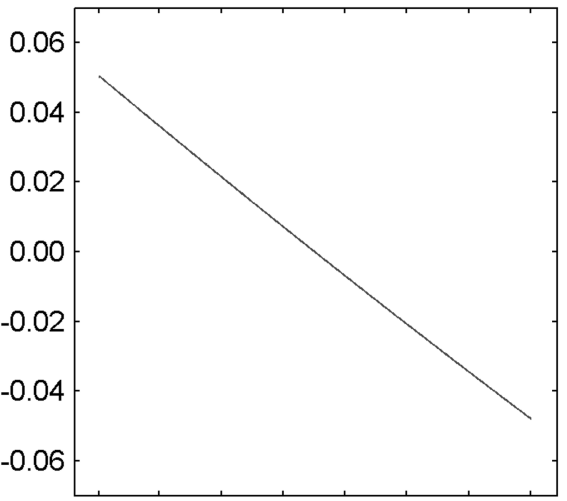

(d)

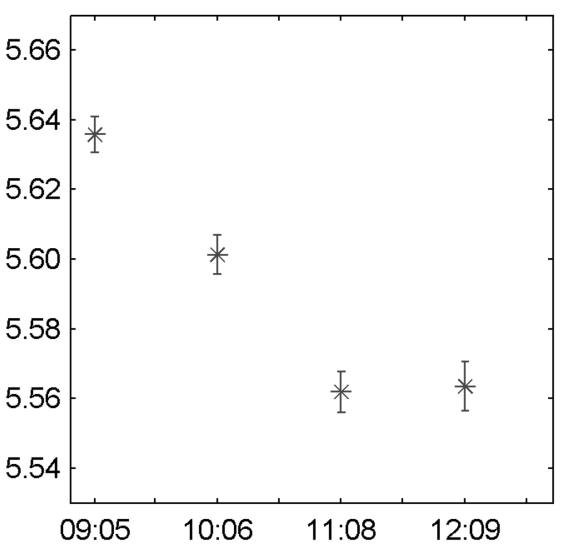

(f)

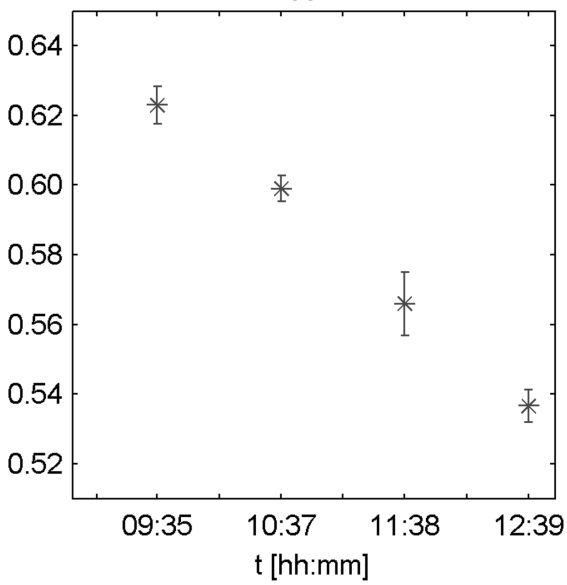

Fig. 5 Drift estimated by F2 S1 model for: a meter 4372, b meter 4373; observations with its standard deviations at lower level for: c meter 4372, d meter 4373 and at higher level for: e meter 4372, f meter 4373 at station AGT03 on April 30th 2013 
(a)

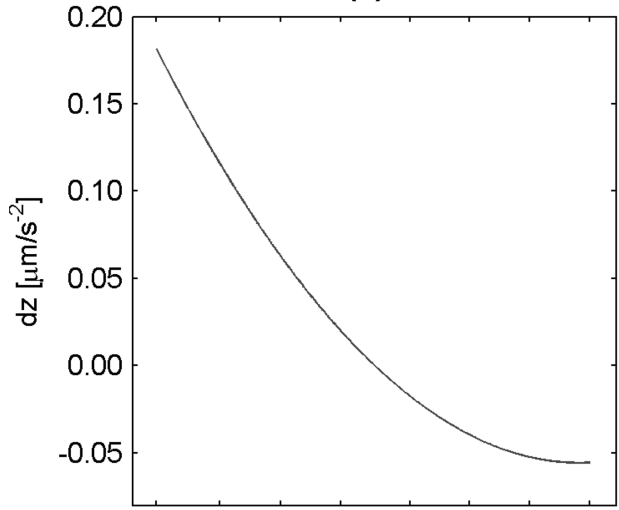

(c)

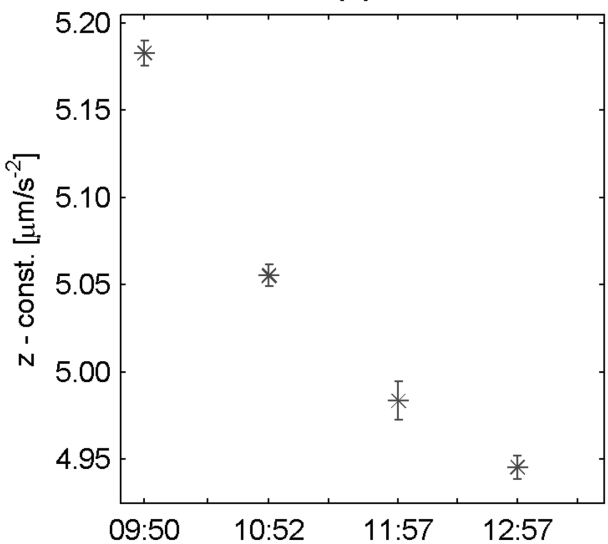

(e)

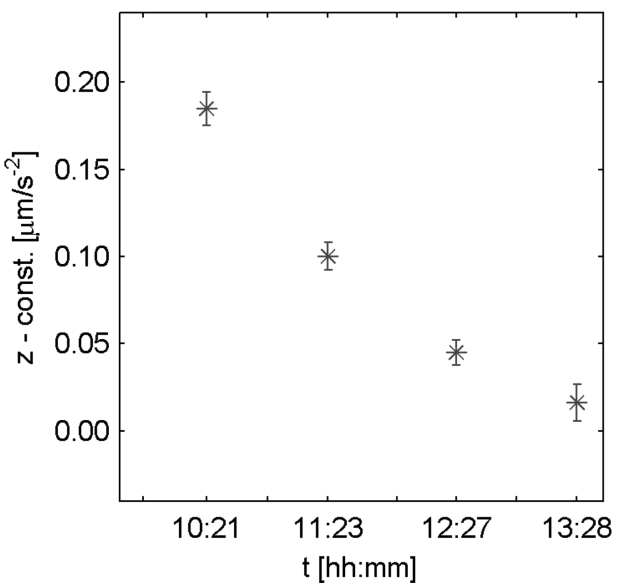

(b)

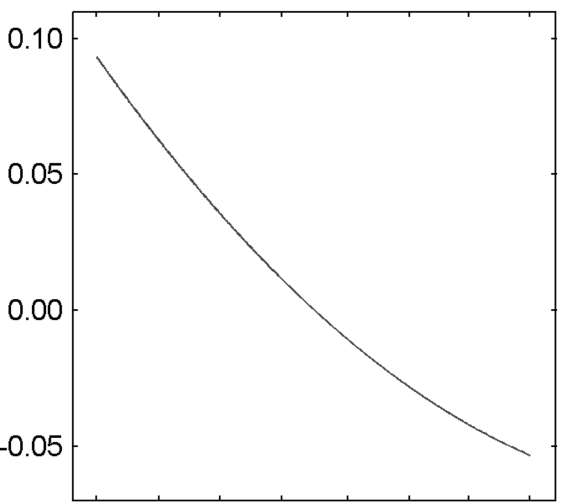

(d)

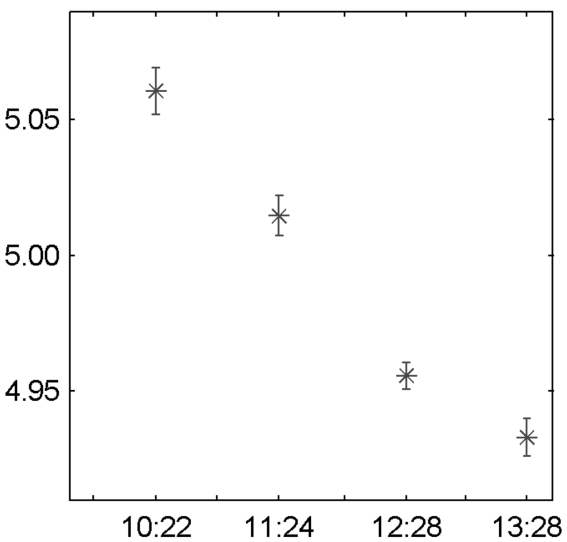

(f)

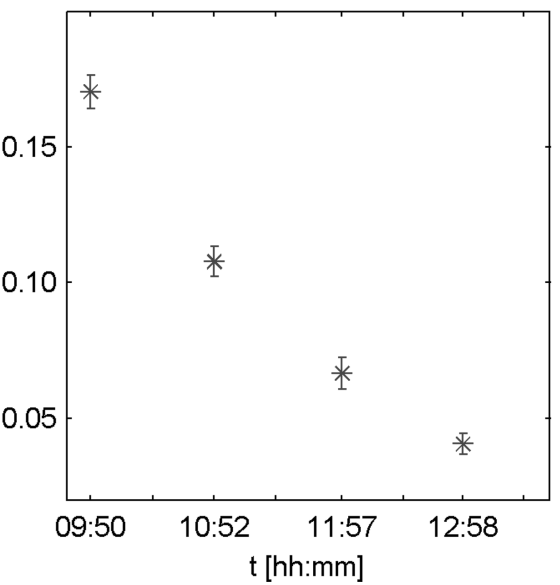

Fig. 6 Drift estimated by F2 S1 model for: a meter 4372, b meter 4373; observations with its standard deviations at lower level for: c meter 4372, d meter 4373 and at higher level for: e meter 4372, f meter 4373 at station AGT03 on October 1st 2014 
(a)

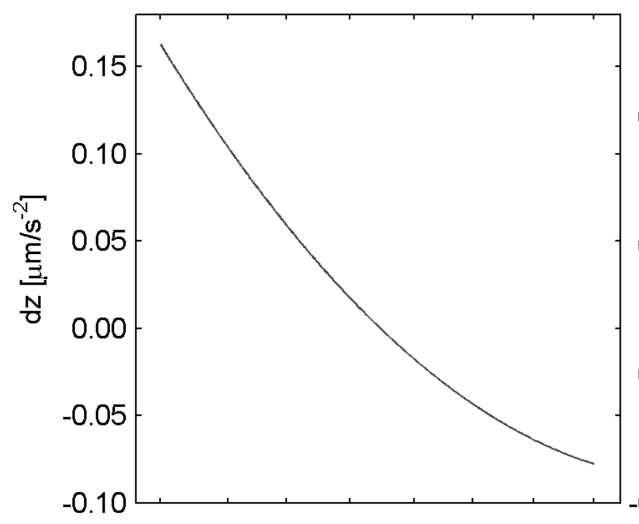

(c)

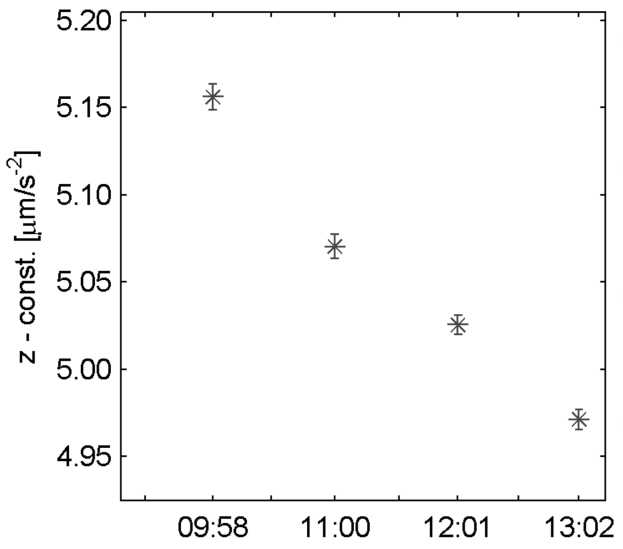

(e)

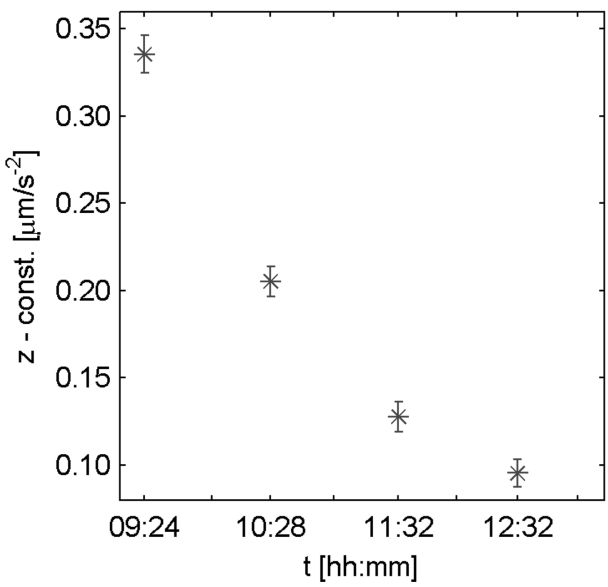

(b)

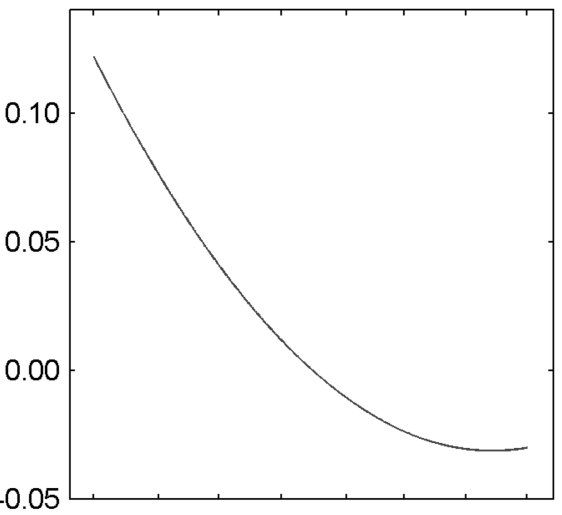

(d)

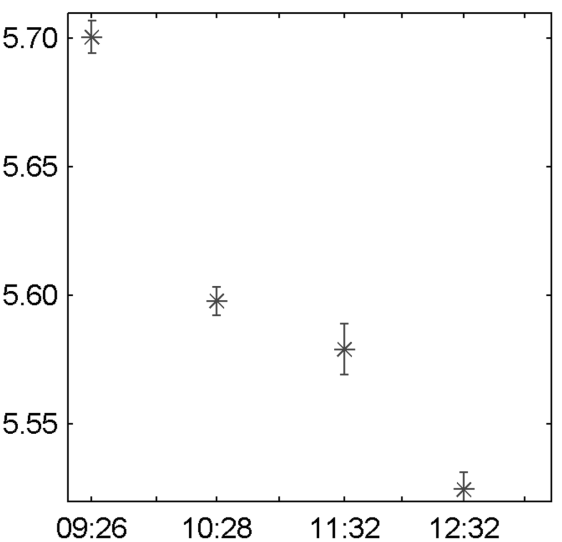

(f)

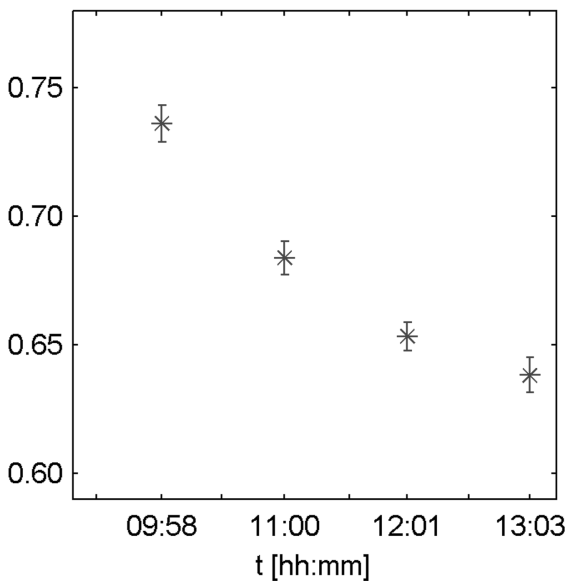

Fig. 7 Drift estimated by F2 S1 model for: a meter 4372, b meter 4373; observations with its standard deviations at lower level for: c meter 4372, d meter 4373 and at higher level for: e meter 4372, f meter 4373 at station AGT03 on October 15th 2014 
observation series. Since there is noticeable correlation of simultaneous readings at two levels, one can conclude that variation is mainly caused by external influence, probably the microseismic.

During the measurements at station AGT02 the sliding roof was partly open because of the extreme proximity of the meter at higher level to the ceiling, in order to make room for the operator (Fig. 2). Consequently, the meters were partly exposed to external influences; particularly light breeze during the last two observation series on April 9th 2013, which mostly influenced the meter at higher level. Measurements at station AGT03 were performed in closed room.

\section{Calculations}

Scintrex Autograv CG-3M is a gravity meter with automatic electronic and software control of the measurement process. Instrumental corrections (i.e. stationary drift correction, tilt correction and temperature compensation) are automatically applied by the meter. In addition, the meter calculates gravimetric tidal reduction according to Longman formula and (as selected) applies it to gravity reading in real time (Scintrex 1998). Additionally, data of all four determinations have been processed using Berger tidal reduction computed by SeeG3 software version 2.1210 from Micro-g Solutions and Timmen and Wenzel reduction computed by PETGTAB software version 3.01 (Timmen and Wenzel 1994) using Tamura (1987) tidal potential catalogue. Applying different tidal reductions has not resulted in any change of estimated vertical gravity gradient nor its standard deviation, but only in change of estimated drift parameters up to some extent.

As stated in previous section, one reading consisted of $60 \mathrm{~s}$ signals, automatically averaged by the meter. One observation series comprised 15 such readings. Thus, prior to adjustment, value of each observation and its standard deviation was calculated, as weighted mean from 15 readings, with weights calculated from standard deviations. Also, barometric reduction, to account for pressure change during the measurements, where applied. Reduced observations with its standard deviations for all determinations and both meters are depicted by Figs. 4, 5, 6 and $7 \mathrm{c}$ and $\mathrm{d}$ at lower level as well as e and $\mathrm{f}$ at higher level, for meters 4372 and 4373 respectively.

The adjustment was preformed according to Gauss-Markov model and least square principle. The values introduced in adjustment as measurements were differences of subsequent observations (computed as weighted mean with barometric reduction applied). Given that measurements were performed only at two levels, the vertical gravity gradient is depicted by a linear model. Since the actual vertical gradient is not a linear function of height, in the paper the term precision is used rather than accuracy of estimated vertical gravity gradient. Four adjustment models have been applied: combinations of two functional models and two stochastic models.

The first functional model (F1) involved linear daily drift corrections:

$$
\Delta z_{i, j}+v_{k}=W_{z z} \Delta h_{i, j}+d^{g r}\left(t_{j}-t_{i}\right),
$$

where $\Delta z_{i, j}=z_{j}-z_{i}$ is a measurement, $v_{k}$ measurement correction, $W_{z z}$ unknown vertical gravity gradient, $\Delta h_{i, j}=h_{j}-h_{i}$ difference of sensor heights for subsequent observations $z_{i}$ and $z_{j}, d^{g r}$ linear daily drift coefficient for gravity meter $g r$ also $t_{i}$ and $t_{j}$ are times of respective observations $z_{i}$ and $z_{j}$. 
Second functional model (F2) involved quadratic daily drift correction:

$$
\Delta z_{i, j}+v_{k}=W_{z z} \Delta h_{i, j}+d_{1}^{g r}\left(t_{j}-t_{i}\right)+d_{2}^{g r}\left[\left(t_{j}-t_{0}\right)^{2}-\left(t_{i}-t_{0}\right)^{2}\right],
$$

where $d_{1}^{g r}$ is linear, and $d_{2}^{g r}$ quadratic daily drift coefficient and $t_{0}$ is a mean time of observations of corresponding gravity meter.

Since measurements are derived as differences of subsequent observations, subsequent measurements are correlated. Such mathematical correlation was taken into account by the first stochastic model (S1). Accordingly, the weight matrix of derived measurements was composed of symmetric block matrices each corresponding to specific gravity meter:

$$
\mathbf{P}=\left[\begin{array}{cc}
\mathbf{P}_{\Delta z}^{1} & \mathbf{0} \\
\mathbf{0} & \mathbf{P}_{\Delta z}^{2}
\end{array}\right],
$$

where each block matrices was computed according to weight propagation law (Feil 1989, 1990) from:

$$
\left(\mathbf{P}_{\Delta z}^{\mathbf{g r}}\right)^{-1}=\mathbf{A}_{\Delta}\left(\mathbf{P}_{\mathbf{z}}^{\mathrm{gr}}\right)^{-1} \mathbf{A}_{\Delta}^{\mathrm{T}}
$$

where $\boldsymbol{P}_{z}^{g r}$ is a diagonal weight matrix of independent gravity observation, with weights defined as inversely proportional to observations' variances and:

$$
\mathbf{A}_{\Delta}=\left[\begin{array}{cccc}
-1 & 1 & & \\
& \ddots & \ddots & \\
& & -1 & 1
\end{array}\right]
$$

Second stochastic model (S2) totally neglects mathematical correlation and treats measurements as equally precise. Thus, the weight matrix was equal to identity matrix.

All calculations were performed by self-written programming functions in Matlab.

\section{Results}

Estimated vertical gravity gradient (in $\mu \mathrm{ms}^{-2} / \mathrm{m}$ ), and drift parameters (in $\mu \mathrm{ms}^{-2} /$ day and $\mu \mathrm{ms}^{-2} / \mathrm{day}^{2}$ for linear and quadratic drift parameter respectively) with its standard

Table 2 Estimated vertical gravity gradient and drift values at station AGT02 on April 9th 2013

\begin{tabular}{llllllllllll}
\hline Gravity meter & & \multicolumn{3}{c}{ F1 and S1 } & \multicolumn{2}{c}{ F1 and S2 } & \multicolumn{2}{c}{ F2 and S1 } & \multicolumn{2}{c}{ F2 and S2 } \\
\hline 4372 and 4373 & $W_{z z}$ & $\sigma_{W z z}$ & -3.230 & 0.008 & -3.228 & 0.005 & -3.232 & 0.005 & -3.229 & 0.004 \\
& $d_{1}^{4372}$ & $\sigma_{d 1}$ & -0.435 & 0.157 & -0.406 & 0.372 & -0.422 & 0.100 & -0.439 & 0.280 \\
& $d_{2}^{4372}$ & $\sigma_{d 2}$ & & & & & 7.117 & 2.145 & 8.665 & 3.007 \\
& $d_{1}^{4373}$ & $\sigma_{d 1}$ & -0.154 & 0.144 & -0.187 & 0.373 & -0.085 & 0.095 & -0.209 & 0.280 \\
& $d_{2}^{4373}$ & $\sigma_{d 2}$ & & & & & 5.304 & 1.946 & 4.498 & 3.024 \\
4372 & $W_{z z}$ & $\sigma_{W z z}$ & -3.224 & 0.012 & -3.226 & 0.008 & -3.228 & 0.005 & -3.227 & 0.004 \\
& $d_{1}^{4372}$ & $\sigma_{d 1}$ & -0.457 & 0.160 & -0.427 & 0.407 & -0.439 & 0.069 & -0.453 & 0.209 \\
& $d_{2}^{4372}$ & $\sigma_{d 2}$ & & & & & 6.962 & 1.440 & 8.623 & 2.229 \\
& $W_{z z}$ & $\sigma_{W z z}$ & -3.233 & 0.010 & -3.230 & 0.007 & -3.235 & 0.008 & -3.230 & 0.007 \\
& $d_{1}^{4373}$ & $\sigma_{d 1}$ & -0.152 & 0.155 & -0.206 & 0.376 & -0.082 & 0.123 & -0.221 & 0.366 \\
& $d_{2}^{4373}$ & $\sigma_{d 2}$ & & & & & 5.374 & 2.526 & 4.463 & 3.917 \\
\hline
\end{tabular}


deviations for all four adjustment models applied to measurements of both gravity meters and of each gravity meter separately are presented in Tables 2, 3, 4 and 5. Since F2 functional model is, in subsequent section, evaluated as better one and S1 stochastic model as one that better suits F2, respective results are highlighted. Subplots (a) and (b) of Figs. 4, 5, 6 and 7 depict drift estimated by F2 and S1 model. As regards standard deviations of estimated parameters as well as differences of vertical gravity gradient from adjustments for each gravity meter data separately, one can notice that results from the last determination are of somewhat lower quality as compared to first three determinations.

In addition to adjustments according to models described in previous section, measurements of all four determinations are processed according to "step by step" calculation. Specifically, drift parameters are determined from all readings by least squares fitting. All readings of one level (15 readings times 4 per a level) are averaged after drift removal. Vertical gravity gradient values from measurements of each meter are then determined according to Eq. (1). Its standard deviations are determined according to variance propagation law from standard deviations of average readings at two levels. Finally, mean vertical gravity gradient from both meters is determined with its standard deviation, determined according to variance propagation law from standard deviations for specific meter. Drift parameters (in $\mu \mathrm{ms}^{-2} /$ day and $\mu \mathrm{ms}^{-2} / \mathrm{day}^{2}$ for linear and quadratic drift parameter respectively) and vertical gravity gradients (in $\mu \mathrm{ms}^{-2} / \mathrm{m}$ ), and respective standard deviation determined according to such "step by step" calculation together with vertical gradient values from F2 and S1 adjustment model are presented in Table 6. While there is no significant difference in vertical gravity gradient values nor its standard deviations (except for station AGT03 on October 15th 2014), reliability of drift parameters from "step by step" calculations is significantly higher as compared to four adjustment models (Tables 2, 3, 4, 5). However, one must have in mind that "step by step" calculation neglects mathematical correlation of readings after drift removal as well as uncertainties of drift parameters. In addition standard deviation of final vertical gravity gradient determined by "step by step" calculation depends only on standard deviations of vertical gravity gradients for specific meter not considering mutual agreement of vertical gravity gradient values.

Value of vertical gravity gradient determined at station AGT03 on April 30th 2013 is approximately $60 \mathrm{nms}^{-2} / \mathrm{m}$ lower than other two determinations in October 2014

Table 3 Estimated vertical gravity gradient and drift values at station AGT03 on April 30th 2013

\begin{tabular}{llllllllllll}
\hline Gravity meter & & \multicolumn{3}{c}{ F1 and S1 } & \multicolumn{2}{c}{ F1 and S2 } & \multicolumn{2}{c}{ F2 and S1 } & \multicolumn{3}{c}{ F2 and S2 } \\
\hline 4372 and 4373 & $W_{z z}$ & $\sigma_{W z z}$ & -4.121 & 0.007 & -4.119 & 0.005 & -4.119 & 0.003 & -4.119 & 0.003 \\
& $d_{1}^{4372}$ & $\sigma_{d 1}$ & -1.373 & 0.155 & -1.613 & 0.362 & -1.518 & 0.082 & -1.615 & 0.249 \\
& $d_{2}^{4372}$ & $\sigma_{d 2}$ & & & & & 10.254 & 1.761 & 10.967 & 2.904 \\
& $d_{1}^{4373}$ & $\sigma_{d 1}$ & -0.653 & 0.102 & -0.687 & 0.363 & -0.662 & 0.052 & -0.686 & 0.249 \\
& $d_{2}^{4373}$ & $\sigma_{d 2}$ & & & & & 0.244 & 1.088 & -0.014 & 2.932 \\
4372 & $W_{z z}$ & $\sigma_{W z z}$ & -4.129 & 0.015 & -4.120 & 0.008 & -4.123 & 0.005 & -4.120 & 0.004 \\
& $d_{1}^{4372}$ & $\sigma_{d 1}$ & -1.412 & 0.216 & -1.619 & 0.480 & -1.532 & 0.069 & -1.622 & 0.254 \\
& $d_{2}^{4372}$ & $\sigma_{d 2}$ & & & & & 10.056 & 1.457 & 10.975 & 2.943 \\
& $W_{z z}$ & $\sigma_{W z z}$ & -4.117 & 0.005 & -4.119 & 0.004 & -4.117 & 0.005 & -4.119 & 0.005 \\
& $d_{1}^{4373}$ & $\sigma_{d 1}$ & -0.667 & 0.057 & -0.693 & 0.246 & -0.669 & 0.064 & -0.693 & 0.275 \\
& $d_{2}^{4373}$ & $\sigma_{d 2}$ & & & & & 0.290 & 1.314 & -0.014 & 3.215 \\
\hline
\end{tabular}


Table 4 Estimated vertical gravity gradient and drift values at station AGT03 on October 1st 2014

\begin{tabular}{llllllllllll}
\hline Gravity meter & & \multicolumn{3}{c}{$\mathrm{F} 1$ and S1 } & \multicolumn{2}{c}{ F1 and S2 } & \multicolumn{2}{c}{ F2 and S1 } & \multicolumn{2}{c}{ F2 and S2 } \\
\hline 4372 and 43733 & $W_{z z}$ & $\sigma_{W z z}$ & -4.063 & 0.007 & -4.065 & 0.004 & -4.061 & 0.003 & -4.064 & 0.002 \\
& $d_{1}^{4372}$ & $\sigma_{d 1}$ & -1.571 & 0.151 & -1.609 & 0.328 & -1.517 & 0.064 & -1.560 & 0.190 \\
& $d_{2}^{4372}$ & $\sigma_{d 2}$ & & & & & 10.374 & 1.552 & 10.469 & 2.186 \\
& $d_{1}^{4373}$ & $\sigma_{d 1}$ & -0.960 & 0.116 & -1.028 & 0.329 & -0.960 & 0.049 & -1.018 & 0.190 \\
& $d_{2}^{4373}$ & $\sigma_{d 2}$ & & & & & 3.335 & 1.208 & 2.107 & 2.192 \\
4372 & $W_{z z}$ & $\sigma_{W z z}$ & -4.070 & 0.016 & -4.066 & 0.008 & -4.065 & 0.003 & -4.065 & 0.002 \\
& $d_{1}^{4372}$ & $\sigma_{d 1}$ & -1.551 & 0.191 & -1.600 & 0.419 & -1.509 & 0.036 & -1.553 & 0.112 \\
& $d_{2}^{4372}$ & $\sigma_{d 2}$ & & & & & 10.204 & 0.858 & 10.455 & 1.282 \\
4373 & $W_{z z}$ & $\sigma_{W z z}$ & -4.058 & 0.007 & -4.063 & 0.004 & -4.059 & 0.005 & -4.063 & 0.005 \\
& $d_{1}^{4373}$ & $\sigma_{d 1}$ & -0.954 & 0.083 & -1.018 & 0.247 & -0.957 & 0.065 & -1.010 & 0.261 \\
& $d_{2}^{4373}$ & $\sigma_{d 2}$ & & & & & 3.287 & 1.613 & 2.099 & 2.992 \\
\hline
\end{tabular}

Table 5 Estimated vertical gravity gradient and drift values at station AGT03 on October 15th 2014

\begin{tabular}{llllllllllll}
\hline Gravity meter & & \multicolumn{3}{c}{ F1 and S1 } & \multicolumn{2}{c}{ F1 and S2 } & \multicolumn{2}{c}{ F2 and S1 } & \multicolumn{2}{c}{ F2 and S2 } \\
\hline \multirow{4}{*}{4372 and 4373} & $W_{z z}$ & $\sigma_{W z z}$ & -4.064 & 0.010 & -4.065 & 0.006 & -4.062 & 0.006 & -4.065 & 0.004 \\
& $d_{1}^{4372}$ & $\sigma_{d 1}$ & -1.499 & 0.182 & -1.770 & 0.459 & -1.575 & 0.117 & -1.732 & 0.346 \\
& $d_{2}^{4372}$ & $\sigma_{d 2}$ & & & & & 7.149 & 2.605 & 9.027 & 3.963 \\
& $d_{1}^{4373}$ & $\sigma_{d 1}$ & -1.006 & 0.159 & -1.037 & 0.461 & -1.000 & 0.099 & -1.012 & 0.347 \\
& $d_{2}^{4373}$ & $\sigma_{d 2}$ & & & & & 7.978 & 2.299 & 9.131 & 4.004 \\
4372 & $W_{z z}$ & $\sigma_{W z z}$ & -4.071 & 0.014 & -4.071 & 0.008 & -4.071 & 0.008 & -4.072 & 0.005 \\
& $d_{1}^{4372}$ & $\sigma_{d 1}$ & -1.518 & 0.167 & -1.821 & 0.438 & -1.599 & 0.104 & -1.785 & 0.282 \\
& $d_{2}^{4372}$ & $\sigma_{d 2}$ & & & & & 7.134 & 2.295 & 9.152 & 3.211 \\
4373 & $W_{z z}$ & $\sigma_{W z z}$ & -4.059 & 0.015 & -4.059 & 0.009 & -4.055 & 0.009 & -4.059 & 0.006 \\
& $d_{1}^{4373}$ & $\sigma_{d 1}$ & -1.027 & 0.187 & -1.085 & 0.482 & -1.026 & 0.106 & -1.062 & 0.360 \\
& $d_{2}^{4373}$ & $\sigma_{d 2}$ & & & & & 8.189 & 2.415 & 9.215 & 4.136 \\
\hline
\end{tabular}

(Table 6). Though, respective standard deviations of $3-6 \mathrm{nms}^{-2} / \mathrm{m}$ and disagreement of values from adjustment of measurements of each gravity meter separately of only 5 and 15 (for the last determination), imply that measurement procedure and calculations are properly applied. However measurements on April 30th 2013 were positioned with horizontal shift of about $20 \mathrm{~cm}$ as compared to measurements in 2014 .

Difference between newly determined vertical gravity gradient value at station AGT02 (Table 6) and one determined in June 1996 (Table 1) amount $8 \mathrm{nms}^{-2} / \mathrm{m}$, in spite of difference in reference levels. At station AGT03 the difference amounts $-29,29$ and $28 \mathrm{nms}^{-2} / \mathrm{m}$ for respective determination. Standard deviations of newly determined vertical gravity gradient are significantly smaller than ones determined in 1996. The value from June 1996 in between values determined in April 2013 and October 2014, can imply on variation in vertical gravity gradient caused by seasonal hydrological effects. Abundant 
Table 6 Results of "step by step" calculations and vertical gradient values from F2 and S1 adjustment model

\begin{tabular}{|c|c|c|c|c|c|c|c|c|c|c|}
\hline Gravity meter & & & \multicolumn{2}{|c|}{ AGT02 09/04/ } & \multicolumn{2}{|c|}{$\begin{array}{l}\text { AGT03 30/04/ } \\
2013\end{array}$} & \multicolumn{2}{|c|}{$\begin{array}{l}\text { AGT03 01/10/ } \\
2014\end{array}$} & \multicolumn{2}{|c|}{$\begin{array}{l}\text { AGT03 15/10/ } \\
2014\end{array}$} \\
\hline \multirow[t]{3}{*}{4372} & $W_{z z}$ & $\sigma_{W z z}$ & -3.230 & 0.006 & -4.118 & 0.004 & -4.067 & 0.005 & -4.070 & 0.005 \\
\hline & $d_{1}^{4372}$ & $\sigma_{d l}$ & -0.470 & 0.068 & -1.553 & 0.057 & -1.534 & 0.058 & -1.633 & 0.053 \\
\hline & $d_{2}^{4372}$ & $\sigma_{d 2}$ & 6.046 & 1.470 & 11.420 & 1.296 & 9.297 & 1.299 & 8.534 & 1.225 \\
\hline \multirow[t]{3}{*}{4373} & $W_{z z}$ & $\sigma_{W z z}$ & -3.227 & 0.005 & -4.118 & 0.004 & -4.062 & 0.004 & -4.059 & 0.004 \\
\hline & $d_{1}^{4373}$ & $\sigma_{d 1}$ & -0.060 & 0.059 & -0.645 & 0.047 & -0.993 & 0.046 & -1.037 & 0.049 \\
\hline & $d_{2}^{4373}$ & $\sigma_{d 2}$ & 5.151 & 1.272 & 1.210 & 1.066 & 2.457 & 1.035 & 8.312 & 1.169 \\
\hline Mean & $W_{z z}$ & $\sigma_{W z z}$ & -3.229 & 0.004 & -4.118 & 0.003 & -4.065 & 0.003 & -4.064 & 0.003 \\
\hline F2 S1 & $W_{z z}$ & $\sigma_{W z z}$ & -3.232 & 0.005 & -4.119 & 0.003 & -4.061 & 0.003 & -4.062 & 0.006 \\
\hline
\end{tabular}

snowfalls during beginning of 2013 and snow cover that partly retained even during the measurement in April go in favour of such assumption.

\section{Investigation on most appropriate adjustment model}

Separate adjustment for each combination of functional and stochastic model was carried out for measurements of both gravity meters and for each gravity meter separately. In order to find most appropriate adjustment model, the results have been compared and evaluated on the basis of several criteria:

- Standard deviations of estimated vertical gravity gradient,

- Standard deviations of estimated daily drift coefficients,

- Standard deviations of measurements and adjusted measurements,

- Differences of vertical gravity gradient from adjustments for each gravity meter data separately.

\subsection{Evaluation of functional models}

For adjustments of both gravity meter data, standard deviations of vertical gravity gradient are approximately 20-60\% smaller for F2 (quadratic drift) functional model as compared to F1 (linear drift) (Tables 2, 3, 4, 5). For adjustments of 4372 meter data, the differences in standard deviations of vertical gravity gradient are even greater and amount 38-80\% in favour of F2 functional model, while for adjustments of 4373 meter data difference is significant only for the last determination (October 15th 2014). Latter is in accordance with much smaller quadratic drift coefficient estimated for 4373 meter, then for 4372 meter on April 9th, and close to zero on April 30th 2013.

Ratios are about the same for standard deviations of measurements, while for standard deviations of adjusted measurements the ratios are smaller, and even go in favour of F1 model for adjustment of 4373 meter data on April 30th 2013, when the drift was linear.

Differences of vertical gravity gradient from adjustment for each gravity meter data separately are smaller up to $50 \%$ for F2 functional model, except for the last determination (October 15th 2014) where the differences are even to some extent larger. However, its 
absolute values are all in limits of standard deviation values and for F2 functional model amount from 2 to $7 \mathrm{nms}^{-2} / \mathrm{m}$, with exception of the last determination (13 and $\left.15 \mathrm{nms}^{-2} / \mathrm{m}\right)$.

One can come upon conclusion than it is expedient to incorporate quadratic daily drift into a functional model, since in case of linear drift it does not significantly affect the quality assessment (except standard deviations of adjusted measurements up to some extent), while in case of quadratic drift it leads to significantly smaller standard deviations and more consistent vertical gradient values.

\subsection{Evaluation of stochastic models}

Results of comparison of stochastic models are rather different in case of F1 functional model as compared to F2 model.

As for F1 model, the standard deviations of vertical gravity gradient are approximately 20-50 \% smaller for S2 (without correlation) stochastic model as compared to S1 (with correlation) (Table 2, 3, 4, 5). On the other hand for F2 model, differences between standard deviations of vertical gravity gradient for S1 and S2 stochastic models are in general insignificant.

Comparison of standard deviations of daily drift coefficients and standard deviations of measurements and adjusted measurements goes in favour of S1 model. Moreover, differences are much more emphasised in case of F2 functional model.

Accordingly, standard deviations of linear drift coefficients are 1.5-3.5 times greater for S2 model than for S1 model. Moreover, differences are in general larger in case of F2 functional model. Differences of quadratic drift coefficients are less emphasised and amounts from 40 to $150 \%$.

Standard deviations of measurements for S2 model are 35-120\% larger as compared to $\mathrm{S} 1$ model in case of F2 model, and in case of F1 model 5-120\%. Differences of standard deviations of adjusted measurements for F2 model amount 5-60\%, while in case of F1 model, there is no significant difference.

Then again, differences of vertical gravity gradient from adjustment for each gravity meter data separately go in favour of S2 model. Its absolute values amount from 2 to 4 $\mathrm{nms}^{-2} / \mathrm{m}$ for S2 model, while for S1 model from 5 to $7 \mathrm{nms}^{-2} / \mathrm{m}_{\text {and from }} 9$ to $11 \mathrm{nms}^{-2} / \mathrm{m}$, in case of $\mathrm{F} 2$ and $\mathrm{F} 1$ functional model respectively, excluding the last determination (from 12 to $15 \mathrm{nms}^{-2} / \mathrm{m}$ for all models). However, differences are in accordance with respective standard deviation of vertical gravity gradient.

On the basis of compared results, one can come upon conclusion that S1 stochastic model (with correlation) better suits F2 functional model (quadratic drift). In particular, standard deviations of measurements, adjusted measurements and adjusted drift coefficients are significantly smaller, while differences in standard deviations of adjusted vertical gravity gradient are insignificant. Though, adjusted vertical gravity gradients from separate adjustments for each gravity meter data better agree for S2 model.

However, in case of F1 functional model, the results are rather different and go in favour of S2 stochastic model. Two explanations for this can be found in Torge (1989). Firstly, in case of gravity network adjustment, neglecting mathematical correlation of subsequent gravity differences leads to falsification of the gravity values in the order of standard deviations; the estimated precisions are too favourable. In case of gravity gradient determination from gravity differences, same take place with standard deviations of estimated gravity gradients. Yet, Torge (1989) also states that frequently it does not make sense to take this mathematical correlation into account since there is the superimposed 
physical correlation caused by incomplete drift modelling and other remaining systematic errors, which generally cannot be determined. Thus, one can conclude that S2 stochastic model better suites F1 functional model. Same is confirmed by differences of vertical gravity gradient from adjustment for each gravity meter data separately.

\section{Number of measurements influence on estimated vertical gravity gradient precision}

In addition to evaluation of adjustment models, investigation on number of measurements influence on estimated gravity gradient precision was carried out. Specifically, one by one

Fig. 8 Vertical gradient values depending on number of measurements: a at station AGT02 on April 9th 2013, b at station AGT03 on April 30th 2013, c at station AGT03 on October 1st 2014, d at station AGT03 on October 15th 2014 (a)

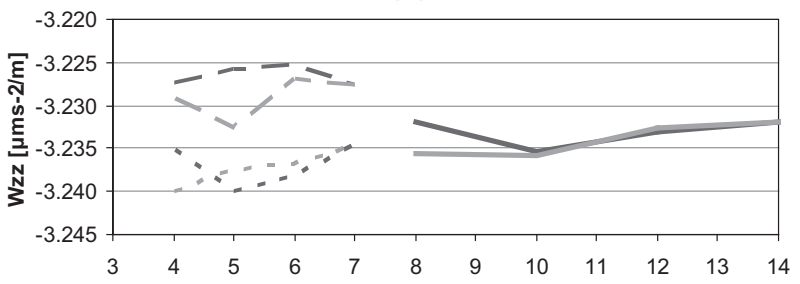

(b)

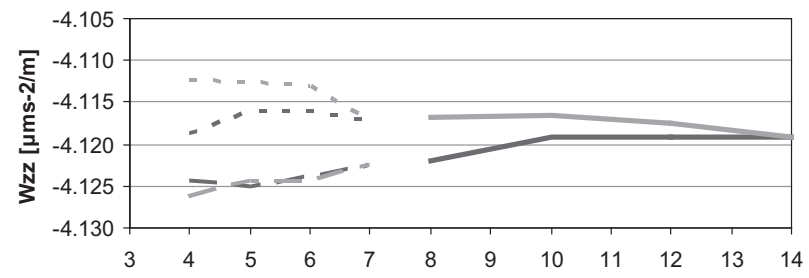

(c)

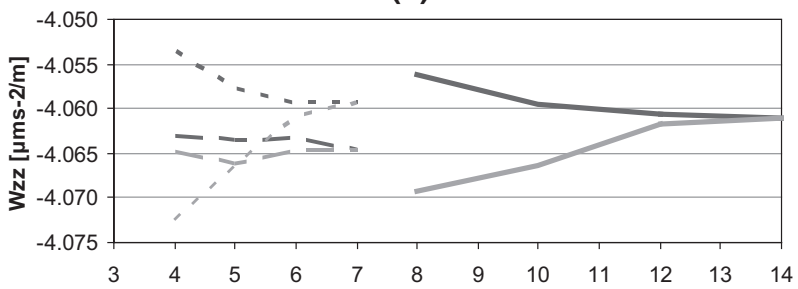

(d)

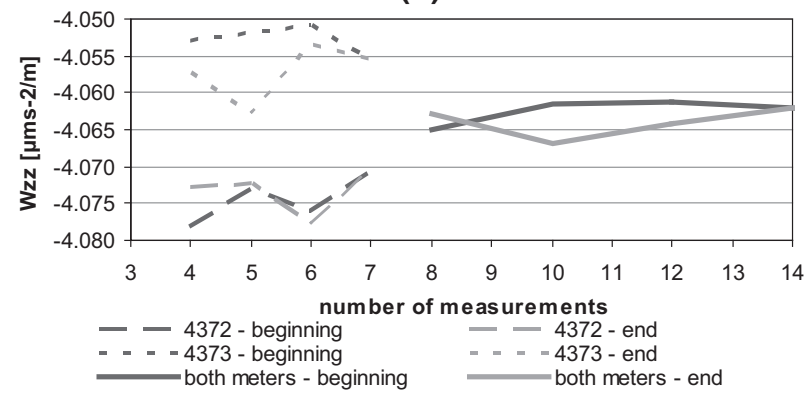


measurement of each gravity meter has been eliminated and respective adjustments have been done. From one to maximum three measurements of each gravity meter, from beginning and from the end of measuring sequence, have been eliminated in order to consider possible remaining hysteresis influence (Fig. 1). Estimated vertical gravity gradient values and its standard deviations are presented in Figs. 8 and 9 respectively. Although no significant difference or trend in estimated vertical gravity gradient values or its standard deviations has been found in case of elimination from the beginning or from the end for first two determinations of vertical gravity gradient (in April 2013), third and four determinations (in October 2014) imply on possible systematic influence in data of 4373 meter (Figs. 8c, d, 9c). Moreover, there is no significant influence of number of measurements on

Fig. 9 Standard deviation of vertical gradient depending on number of measurements: a at station AGT02 on April 9th 2013, b at station AGT03 on April 30th 2013, c at station AGT03 on October 1st 2014, d at station AGT03 on October 15th 2014 (a)

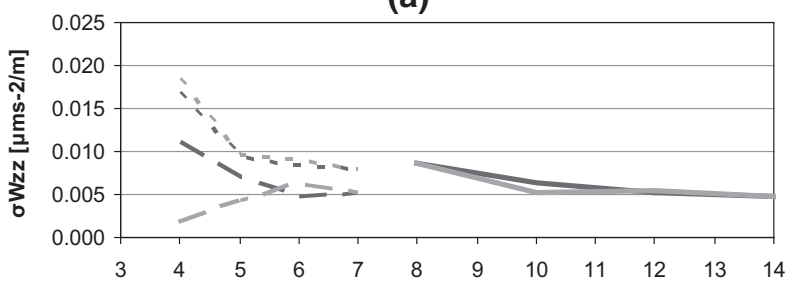

(b)

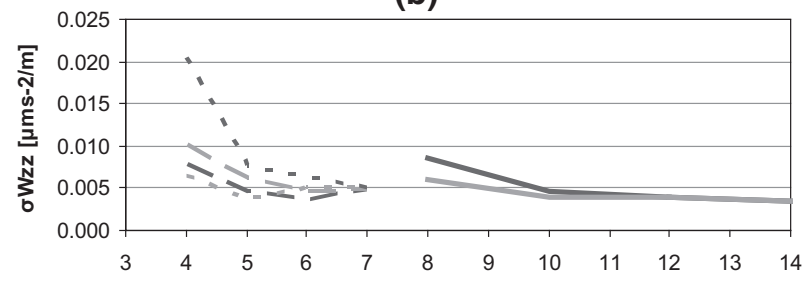

(c)

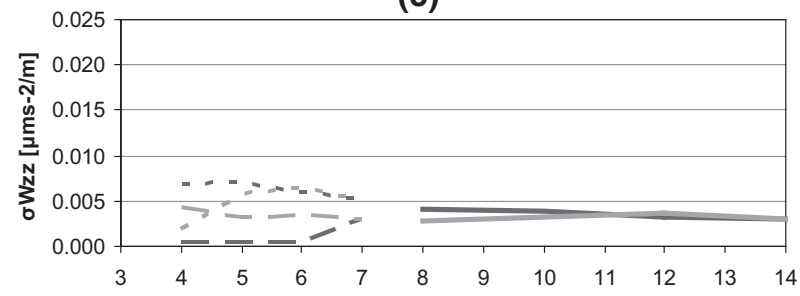

(d)

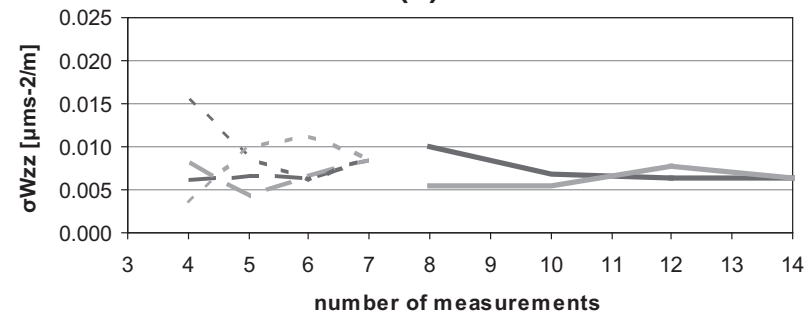


estimated vertical gravity gradient values (Fig. 8) for first two determinations, but for third and four determinations values determined from 4373 meter significantly differ with respect of number of measurements. Although, in general, there is slight increase of standard deviations of estimated vertical gravity gradient with each eliminated measurement, significant jump takes place at three eliminated measurements of each gravity meter (Fig. 9). The jump is more evident for adjustments of each gravity meter data separately than for common adjustments. Same takes place for standard deviations of estimated drift coefficients. Since there is no significant difference between adjustments of 6 or 7 measurements of each gravity meter, further increase of number of measurement probably would not result in increase in precision.

(a)

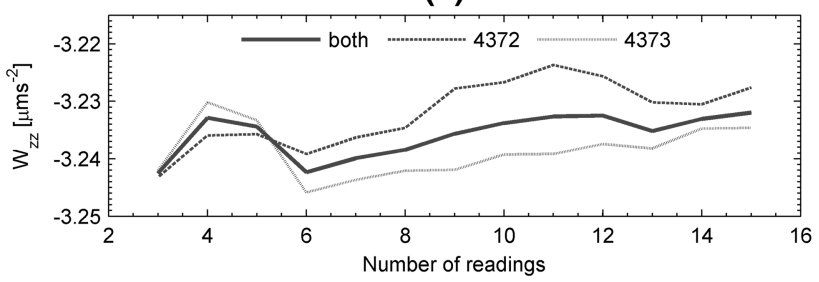

(b)

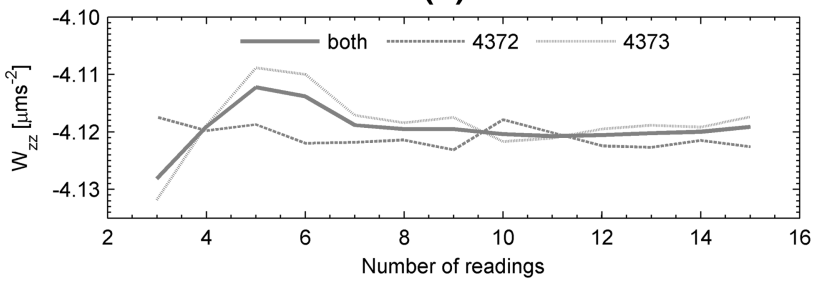

(c)

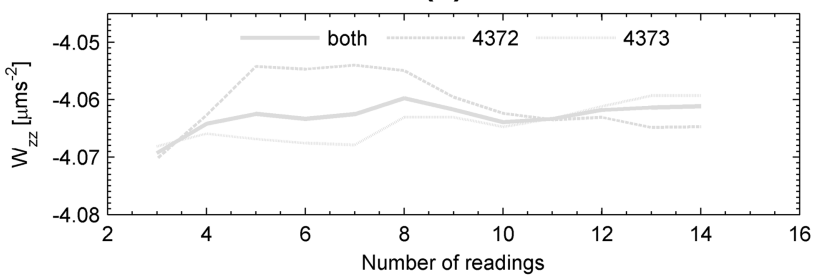

(d)

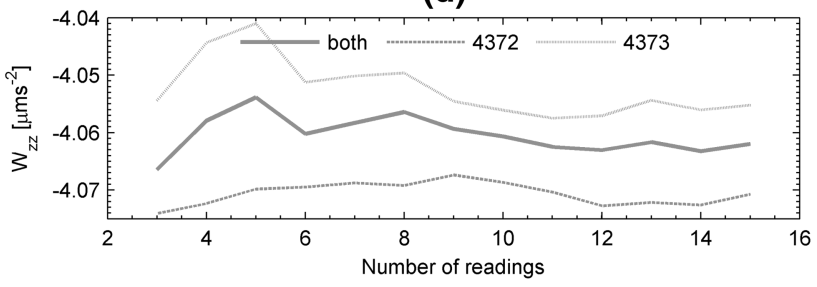

Fig. 10 Vertical gravity gradient values from adjustment of both meters, meter 4372 and meter 4373 data depending on number of readings of each observation series: a at station AGT02 on April 9th 2013, b at station AGT03 on April 30th 2013, $\mathbf{c}$ at station AGT03 on October 1st 2014, d at station AGT03 on October 15th 2014 


\section{Number of readings influence on estimated vertical gravity gradient precision}

In order to reach optimal time efficiency, investigation on number of readings of each observation series on estimated vertical gravity gradient precision was carried out. Specifically, adjustments involving from 3 to 15 first readings of each observation series

(a)

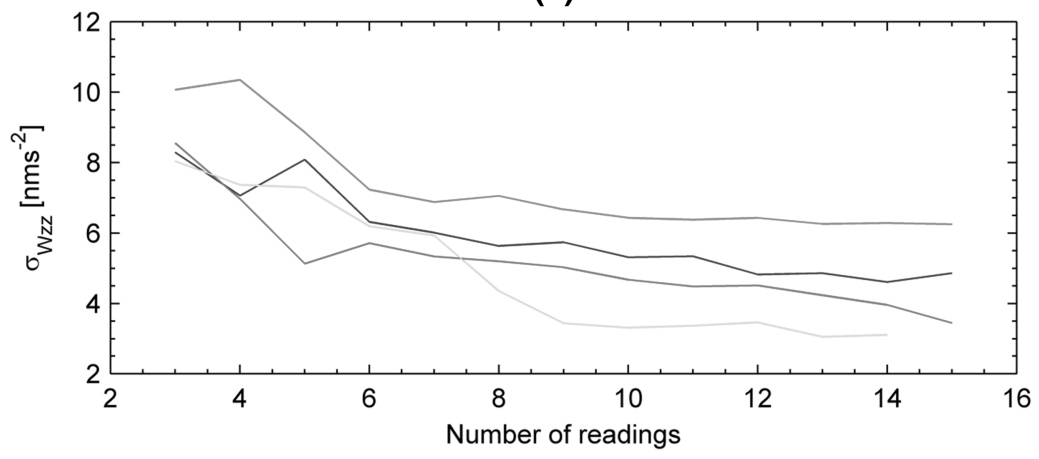

(b)

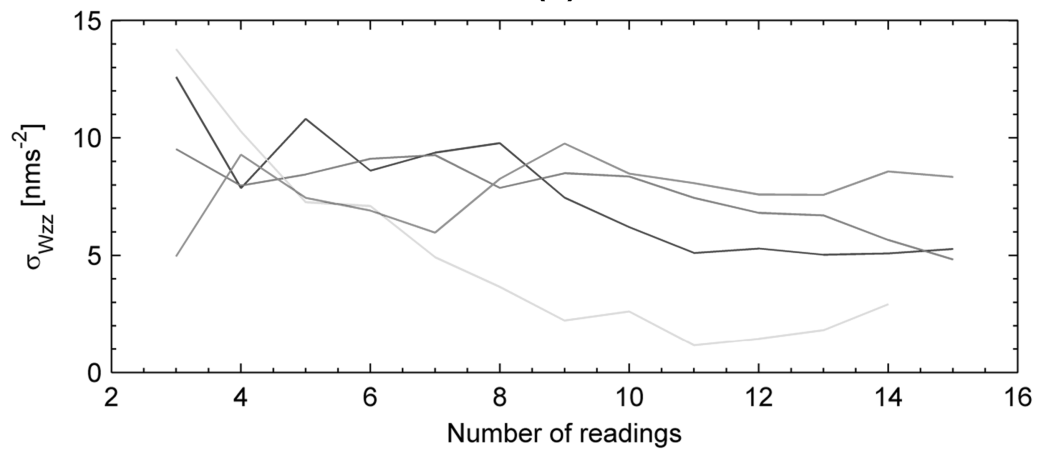

(c)

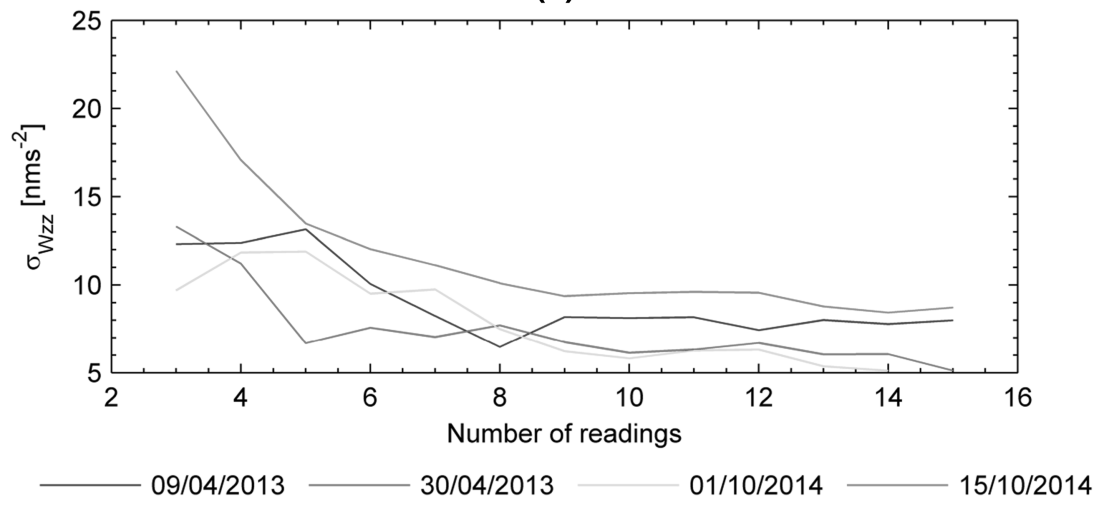

Fig. 11 Standard deviations of vertical gradient for all four determinations depending on number of readings of each observation series for adjustment of: a both meters, b meter 4372 and $\mathbf{c} 4373$ data 
according to F2 functional and S1 stochastic model have been carried out for each determination. Vertical gravity gradient values from adjustment of both meters data in general become stabile with 10 readings included in each observation series Fig. 10. In addition, although behaviour of standard deviations depends on specific meter, increase of number of reading for more than 10 in each observation series does not result in significant increase in precision Fig. 11.

\section{Conclusion}

Applied measurement and adjustment procedures resulted in determination of vertical gravity gradients with high precision. Probably the most significant is elimination of hysteresis effect by stabilization of gravity meters for about an hour, but also increasing the precision of each observation by averaging multiple readings. Investigation on number of readings of each observation series on estimated vertical gravity gradient precision showed that in general it is not expedient to conduct more than 10 readings in each observation series. In addition, used stand of the Wild T4 universal instrument has been proven to be very suitable for high precise gravity measurements. However, its construction does not allow setup at desired reference levels. Determined vertical gravity gradients with standard deviations from 3 to $6 \mathrm{nms}^{-2} / \mathrm{m}$ (Tables 2, 3, 4, 5) allow conversion between reference heights of absolute and relative gravity measurements with precision better than $0.01 \mathrm{mss}^{-2}$. However, if measurements are made only at two levels, levels should be as close as possible to the reference levels of absolute and relative gravity meter used at specific station, in order to eliminate influences of nonlinearity of vertical gradient with height.

Evaluation of applied adjustment functional and stochastic models, on the basis of experimental measurements, showed that it is expedient to incorporate quadratic daily drift into a functional model. Mathematical correlation of subsequent measurements can then be taken into account by stochastic model. However, if daily drift is modelled as a linear function, better results are accomplished if no correlation is taken into account.

On the basis of experimental measurements, it was found that measurement of the gravity difference between two levels in 7 iterations ( 4 observations at each level) by two gravity meters is sufficient for high precision vertical gravity gradient determination. Moreover, measurement in 6 iterations does not provide significantly different results.

It would be expedient to construct a special stand that would allow measurements at least three desired reference levels. Thus further studies could facilitate determination of vertical gravity gradient as a nonlinear function of height. Since measurements at multiple levels result in even greater time consumption, investigations on number of measurements and number of readings of each observation series on vertical gravity gradient reliability become even more important in order to reach optimal time efficiency.

\section{References}

Bašić T, Markovinović D, Rezo M (2006) Basic gravity network of the Republic of Croatia (in Croatian). Geodetski List 60(2):73-91

Csapó G, Völgyesi L (2002) Determination and reliability estimation of vertical gradients based on test measurements. Budapest University of Technology and Economics, Department of Geodesy and Surveying. http://www.agt.bme.hu/volgyesi/gravity/vg_goroe.pdf. Accessed 26 April 2013 
Csapó G, Völgyesi L (2004) New measurements for the determination of local vertical gradients. Rep Geod 69(2):303-308

Dykowski P (2012) Vertical gravity gradient determination for the needs of contemporary absolute gravity measurements-first results. Rep Geod 92(1):23-35

Feil L (1989) Theory of errors and least squares adjustment—part one (in Croatian). Faculty of Geodesy, University of Zagreb, Zagreb

Feil L (1990) Theory of errors and least squares adjustment—part two (in Croatian). Faculty of Geodesy, University of Zagreb, Zagreb

Repanić M, Grgić I, Bašić T (2014) Proposal of zero order gravity network of the Republic of Croatia amendment (in Croatian). Geodetski List 67(1):17-32

Richter B, Wilmes H, Lothhammer A, Falk R, Čolić K, Pribićević B (1999) Absolute gravity measurements in Croatia-a standardized base net for geodynamic, height and gravity studies. In Čolić K, Moritz $\mathrm{H}$ (ed) Proceedings of the Second International Symposium: Geodyn of Alps-Adria Area by means of Terr and Satell Methods, Dubrovnik, Croatia, Sept 28-Oct 2 1998, pp 263-270

Scintrex (1998) CG-3/3M Gravity Meter User's Guide. Scintrex Limited, Ontario

Tamura Y (1987) A harmonic development of the tide-generating potential. Bull Inf Mar Terr 124:9425-9439

Timmen L, Wenzel HG (1994) Worldwide synthetic gravity tide parameters available on internet. BGI Bull Inf 75:32-40

Torge W (1989) Gravimetry. Walter de Gruyter, New York 